\title{
Observations of northern latitude ground-surface and surface-air temperatures
}

Allen D. Woodbury ${ }^{1}$, AKM H. Bhuiyan ${ }^{1,2}$, John Hanesiak ${ }^{2}$, and O. O.

Akinremi ${ }^{3}$.

E1-314 Engineering building, Department of Civil Engineering, University of Manitoba, 15

Gillson Street, Winnipeg, Manitoba, R3T 2N2, Canada. (woodbur@cc.umanitoba.ca)

${ }^{1}$ Department of Civil Engineering,

University of Manitoba

${ }^{2}$ Department of Environment and

Geography, Center for Earth Observation

and Science (CEOS)

${ }^{3}$ Department of Soil Science, all at

University of Manitoba, Winnipeg, Canada

R3T 2N2 
Note that the magnitude of temperature increases reconstructed from borehole records seems to contrast with some proxy based reconstructions of surface air temperature (SAT) that indicate lower amounts of warming over the same period. We present data suggesting that ground and snow cover may bias climate reconstructions based on BT in portions of the Canadian northwest. Eight sites west of the Canadian cordillera, were examined for longterm SAT and GST changes. At seven of these sites precise borehole temperature profiles are used for the first time since the 1960s, thereby exploring the linkage between GST and SAT. New readings were made at four of these locations. All sites showed significant increasing SAT trends, in terms of annual mean minimum and maximum temperatures. Over a 54 year period, the minimum temperatures increased between $1.1^{\circ} \mathrm{C}$ and $1.5^{\circ} \mathrm{C}$ while the maximum increased between $0.8^{\circ} \mathrm{C}$ and $1.5^{\circ} \mathrm{C}$, among those eight stations. Observations of GST at those sites, however, showed no obvious climate induced perturbations. Therefore, we believe that a trend in our area towards an increase in SAT temperatures only over the winter and spring is being masked by freeze thaw and latent energy effects. These results are important, particularly in northern locations where ground and snow cover may play an important role in creating a seasonal bias in GST reconstructions from borehole surveys. 
WOODBURY ET AL.: NORTHER LATITUDE GROUND-SURFACE-AIR TEMPERATURES X - 3

\section{Introduction}

It has been noted that the magnitude of ground surface temperature (GST) increases reconstructed from borehole temperature (BT) records seems to contrast with some proxy based reconstructions of surface air temperatures (SAT; see Zhang, 2005; and references therein). In our region of interest, (northern Canada, greater than $56^{\circ} \mathrm{N}$ and west of the Cordillera), some GST reconstructions (i.e. Majorowicz et al., 2004) show about $0.8^{\circ} \mathrm{C}$ from 1901-1992, but Rodenhuis et al. (2007), based on the SAT record for a period of 1900-2004, show about $1.0-1.5^{\circ} \mathrm{C}$. Other studies in the same region (Lewis et al., 2003) have suggested that ground surface warming and propagation at depth has not occurred as it has in central and eastern Canada. This allowed the authors to calculate equilibrium heat flow data from shallow portions of their boreholes. Lewis et al. (2003) cite the work of Lewis and Wang (1998) which suggests that deforestation affected the thermal regimes of boreholes on a regional scale. Even if true, Lewis and Wang (1998) focused on disturbances on Vancouver Island, much further to the south of the northern sites quoted in Lewis et al. (2003). Nevertheless, an inspection of a subset of the Geologic Survey of Canada (GSC) temperature-depth logs used by Lewis et al. (2003) do indicate a near conductive thermal regime and no obvious climate induced perturbations. This apparent discrepancy between SAT records (Zhang et al., 2000), GST calculations presented in Majorowicz and Safanda (2005) and observations of Lewis et al. (2003); as well as the controversy over Mann and Schmidt's (2003) conjecture about a disconnect between SAT and GST motivated us in finding and examining some of the original GSC borehole sites 
X - 4 WOODBURY ET AL.: NORTHER LATITUDE GROUND-SURFACE-AIR TEMPERATURES

in this region of B.C. and the Yukon. One of the interesting parts of this analysis is that at all of the sites we looked at very little land use changes have occurred for over 25 years.

In this paper, eight sites in north-western Canada, west of the Cordillera, are examined for long-term SAT changes. The selected stations are: White Horse, Ruby Creek, Dease Lake, Hotailuh, Gnat Lake, Buckley Lake, Stikine Site Z, and Ritchie (see supplemental material for locations). At seven of these sites precise temperature profiles observed in the 1960's - 1970's are used to explore the linkage between GSTs and SATs. The borehole logs and their descriptions were obtained from the the Geological Survey of Canada's repository of temperature recordings. We attempt to link the results of new readings at four sites taken in 2006 with those previously, and also to the instrumental atmospheric records for observation and interpretation.

Long term trends in monthly average maximum and minimum temperatures are investigated using the adjusted Canadian gridded (CANGRID) dataset (Zhang et al., 2000) for the eight stations. Two different time series are considered (1950 to 1998 and 1950 to 2003) for long term trend analysis. Seasonal trends (Winter -Dec to Feb, Spring - Mar to May, Summer - Jun to Aug, Autumn - Sep to Nov) are also analyzed using same time series.

\section{Atmospheric Temperature Trend Analysis}

The CANGRID dataset contains monthly temperature and precipitation data that covers Canada. The CANGRID data are adjusted using surrounding stations to ensure a homogeneous time series and corrected for bias due to observational system change, station relocation and so on. The data grid is a polar stereographic projection with a $50 \mathrm{~km}$ 
WOODBURY ET AL.: NORTHER LATITUDE GROUND-SURFACE-AIR TEMPERATURES $\quad \mathrm{X}-5$ spatial resolution. The grid is a 125 (columns) by 95 (rows) matrix. Further details of CANGRID data can be found in Zhang et al. (2000).

The nearest CANGRID data point to each station was used for the atmospheric temperature trend analysis using the Zhang et al. (2000) methodology. The statistical model initially removes the autocorrelation from the time series, then the slope (the linear regression between climate variable and time) and its significance level are obtained from the de-autocorrelated time series. The estimated slope is then used to remove the trend from the original series and resulting residuals are used to obtain a more accurate estimation of the (lag - 1) autocorrelation. To determine the statistical significance of the trend, the confidence interval for the slope is obtained in terms of lower and upper bounds based on the order of all possible slopes (Zhang et al., 2000).

During the study we used Zhang's model to calculate lower and upper bound of slope, and Z-statistics for maximum and minimum temperature for our selected stations extracted from the CANGRID time series (1950 to 2003), and mean annual maximum and minimum temperature results are presented in tables in our supplemental material.

All eight sites show a statistically significant increasing trend, $>95 \%$ in most cases, in annual mean minimum and maximum temperatures. Over the 54 year period, the increase in minimum temperatures has been between $1.1^{\circ} \mathrm{C}$ and $1.5^{\circ} \mathrm{C}$ and the increase in maximum temperatures has ranged between $0.8^{\circ} \mathrm{C}$ and $1.5^{\circ} \mathrm{C}$ over the eight stations. All stations, except for Whitehorse, have larger increases in minimum temperatures compared to maximum temperatures, which is consistent with Zhang et al (2000). Analyses suggest that the annual mean trends are significantly influenced by winter (DJF) and spring 
(MAM) temperature trends as opposed to summer (JJA) and autumn (SON). Mean annual winter minimum temperature trends range between $2^{\circ} \mathrm{C}$ and $4^{\circ} \mathrm{C}$ over the 54 year period, while mean annual winter maximum temperature trends range over $1.9^{\circ} \mathrm{C}$ to $4.2^{\circ} \mathrm{C}$, all being statistically significant to $>90 \%$ confidence. Once again, the minimum temperature trends tend to be slightly larger than the maximum temperature trends at most stations. The spring temperature trends are much smaller than the winter trends (see supplemental material), however, spring trends still remain all positive with most of them statistically significant at the $90 \%$ level. The analysis indicates that summer and autumn do not have any statistically significant temperature trends since all confidence levels are less than $80 \%$, with most of them much lower than this.

\section{Borehole Measurement Techniques}

Temperatures were measured with a portable winch and a platinum resistance temperature detector $(\mathrm{RTD})$. The overall accuracy $\left( \pm 0.01^{\circ} \mathrm{C}\right)$ is controlled by precise calibration in a thermal bath and was confirmed by comparison to a SEABIRD ${ }^{\mathrm{TM}}$ digital-platinum RTD. Field data were recorded the summer of 2006. The earlier Geologic Survey of Canada (GSC) data (and the sites) were described by Jessop et al. (1984) who reported accuracies of $\pm 0.02^{\circ} \mathrm{C}$. Temperature recordings were made at various times, but typically in the mid 1960s to early 1970's.

In selected sites presented below synthetic temperature-depth profiles are also plotted. These theoretical responses are calculated by assuming a series of linear changes of the surface temperature (e.g. Beltrami et al., 2003). The pattern consisted of an average GST increase between 1800 and 1900 of $0.44^{\circ} \mathrm{C}$ and $0.71{ }^{\circ} \mathrm{C}$ from 1900 to 1950 ; followed by 
WOODBURY ET AL.: NORTHER LATITUDE GROUND-SURFACE-AIR TEMPERATURES X - 7

a minor adjustment based on the SAT records at each site. The temperature at surface is assumed constant before 1800. At each site, this synthetic GST history is used as the driving signal for computation of the theoretical temperature at depth (at an appropriate time) and is combined with a linear slope and intercept determined from linear regression of portions of each borehole temperature record. A homogeneous value of thermal diffusivity was used. If the conceptual model of the earth response is correct; namely a direct connection between SAT and GST and a purely 1-D conductive environment, then the observed borehole temperatures should be reasonably reflective of a subsequent temperature propagation from surface.

At one location (Dease Lake) we have additional daily-surface air minimum, maximum temperatures and total precipitation for the period $1945 / 1 / 1$ to $2007 / 12 / 31$. Data was continuous in the period of $1947 / 1 / 1$ to $2005 / 3 / 31$. A small number of missing data were filled by simple linear interpolation. This SAT data combined with the precipitation was used to generate shallow surface soil temperatures using the modified versatile-soil moisture budget model (VSMB; Baier et al., 1979; Akiremi et al., 1996). The model accounts for the prediction of soil moisture content, runoff from rainfall and snowmelt, drainage of moisture out of the root zone, groundwater recharge and soil surface temperature. The soil temperature output from VSMB was then in turn used to generate subsurface borehole temperatures at specific times. Because of the data gap in daily SAT from 2005 to 2006 (time of our survey) we adopted a approach similar to n-factors (Klene et al., 2001) to relate SAT to soil temperatures. The only other adjustment that was made was 
to provide a $1.5^{\circ} \mathrm{C}$ offset temperature to account for differences in average temperature between the weather station and our site.

\section{Discussion}

At Whitehorse, the earlier GSC dataset was obtained in 1976 and is shown on Figure 1. A change in climate in this area over the last two centuries should have caused a temperature perturbation to 100-200 $\mathrm{m}$ depth in this hole, but this is obviously not recorded. The data form an almost perfect straight line.

Two original Ruby creek boreholes were logged to depths of 305 and $350 \mathrm{~m}$ in a granitic batholith. Unfortunately, the original hole collars were destroyed by exploration activities. We managed to log another more recent hole (\#48), quite close (about $100 \mathrm{~m}$ ) to the original holes identified by the GSC (see Figure 1). Note that we used the deeper hole (1973) to obtain the $T(z)$ slope in this case. The water table at depth at this site is not known. Jessop et al. (1984) believed that the thermal gradients in the upper portion of the holes were disturbed by groundwater flow. A comparison between the synthetic $T(z)$ plot and the observed data indicates that the warming of the ground surface and subsequent propagation downward according to a purely conductive heat transfer model has not occurred. Yet, we know the SAT signal at the surface shows a linear increase of about $1.5^{\circ} \mathrm{C}$ over 54 years.

The Dease Lake hole is in a well forested creek area and little vegetative changes have been noted in the area since the 1960s. The water table is at the surface, and the hole was logged without incident. On Figure 2., the black dots represent data taken at various times by the GSC in the period 1966-1968. The most recent data (2006) are yellow 
WOODBURY ET AL.: NORTHER LATITUDE GROUND-SURFACE-AIR TEMPERATURES $\quad \mathrm{X}-9$

triangles and are coincident to one of the GSC profiles. The dotted blue line is the best fit for the entire hole from the earlier GSC data at depth. This should be a straight line to represent a long-term average climatic trends. The thin black line is where the signal in the hole should be, based upon a representative GST signal as described earlier and obviously over predicts the temperature at depth. In purple is the thermal profile to 2006, based on the VSMB generated shallow soil temperatures from 1947. The upward trending curve above $5 \mathrm{~m}$ is suggestive of the yearly thermal cycles and not of climate change. The VSMB generated thermal profile is a good match to data recorded in 2006, thus providing confidence in the simulations.

The original hole at Hotailuh (Figure 3 ) was completed to $427 \mathrm{~m}$ into a granitic batholith and is just a few km from the Gnat Lake site. As mentioned by Jessop et al. (1984) portions of this hole were considered to be disturbed by groundwater flows in fractured horizons (150 m and $350 \mathrm{~m}$ ) within the granite. The water table is at the surface, and the hole was logged without incident. The older GSC data are shown as black rectangles. Only the top $200 \mathrm{~m}$ portion of the hole is plotted, and the results show excellent correspondence between the various data sets over the entire borehole length. No change in surface temperature is evident at this site between 1972 and 2006, a situation that is noticeably different with the SAT record at the site. The upward trending curve above $5 \mathrm{~m}$ is suggestive of the yearly thermal cycles and not climate change. We also show the data recorded by Jessop et al. (1984) for Gnat Lake and Ritchie. The results at the Ritchie site are more tenuous due to the steep topography and may have to be corrected for in a more sophisticated analysis. 
The Buckley site is shown in Figure 4 and only the first $50 \mathrm{~m}$ of the record is plotted. In Figure 4, our simple 1-D simulations show that there is a sensitivity to change between 1800-1969 and 1800-2006 (and therefore 1969-2006). Note that between 1969 and 2006 an additional SAT increase of about $0.8^{\circ} \mathrm{C}$. Also shown on Figure 4 is the actual dataset from Buckley showing 1967, 1971 and 2006 data. Given the GST forcing (see section 3 for details) the dashed line shows what a thermal signal would be to 1969 given a direct connection between GST and SAT. The solid line shows a corresponding signal to 2006. Pure heat conduction, given reasonable and representative parameters, does not reflect the character of the observed data. Note that the difference between the dashed and solid lines is quite noticeable and note also that the field surveys for 1967, 1971 and 2007 are virtually coincident.

\section{Conclusions}

A review of Figures 1-4 shows that the climate signal determined from the SAT record has not propagated an anomalous temperature signal to depth as predicted by a conceptual model of 1-D diffusive heat transport, assuming a direct connection between SAT and GST. We also show that given daily temperature and precipitation data we can generate shallow subsurface soil temperatures which in turn can be used to generate deeper temperature profiles. Comparing the surface air to soil temperatures we see that in the range of air temperatures below minus $10^{\circ} \mathrm{C}$ there is very little if any correlation between the two. A good connection exists above this temperature. Therefore, we speculate that a trend in our area towards an increase in SAT temperatures only over the winter and spring is being masked by freeze-thaw and latent energy effects. We note that the 
WOODBURY ET AL.: NORTHER LATITUDE GROUND-SURFACE-AIR TEMPERATURES X - 11

important summer months, at least from the perspective of signal coupling, shows a flat SAT response. Overall then, no (effective) increase in average climate is imported into the ground.

Lastly Mann and Schmidt (2003), through coupling of GCM's and land surface schemes allowing for snow cover, show that SATs in North America closely track GST only during the warm season (see also an important comment and reply pair by Chapman et al., 2004 and Schmidt and Mann, 2004). During the cold season an insulation effect is dominant and this is supported by Zhang (2005). In our observational area, we have a trend in warmer temperatures in the winter and spring, but flat or cool over the summer. This may then explain why the boreholes do not reflect the GST, and the SAT is disconnected. These results are important, particularly in northern locations where snow and/or ground cover may play an important role in creating a seasonal bias in GST reconstructions from borehole surveys.

\section{Acknowledgments}

The authors would like to express their sincere appreciation to many individuals who supported the field work and these include: Juan Benitez, Scott Dunbar, Jim Reed, Willie Williams, and Gary Woodbury. This work was supported by grants to ADW from the Natural Sciences and Engineering Research Council of Canada.

\section{References}

Akinremi, O.O., McGinn, S.M. and Barr, A.G. (1996), Simulating soil moisture and other components of the hydrological cycle using a water budget approach. Can. J. Soil Sci. 
X - 12 WOODBURY ET AL.: NORTHER LATITUDE GROUND-SURFACE-AIR TEMPERATURES

$76,133142$.

Baier, W., Dyer, J. A. and Sharp, W. R. (1979), The versatile soil moisture budget. Tech. Bull. 87, Agrometeorology Section, Research Branch, Agriculture Canada, Ottawa, ON. $52 \mathrm{pp}$

Beltrami, H., C. Gosselin, and J.C. Mareschal (2003). Ground surface temperatures in Canada: Spatial and temporal variability, Geophysical Research Letters, 30 (10), 10.1029/2003GL017144.

Chapman, D. S., M. G. Bartlett, and R. N. Harris (2004), Comment on Ground vs. surface air temperature trends: Implications for borehole surface temperature reconstructions by M. E. Mann and G. Schmidt, Geophys. Res. Lett., Vol. 31, No. 7, L0720510.1029/2003GL019054.

Klene, A.E., Nelson, F.E., Shiklomanoy, N.I. and K. Hinkel (2001), The N-Factor in Natural Landscapes: Variability of Air and Soil-Surface Temperatures, Kuparuk River Basin, Alaska, U.S.A. Arctic, Antarctic, and Alpine Research, Vol. 33, No. 2, pp. $140-148$.

Jessop, A.M., Souther, J.G., Lewis, T.J. and A.S. Judge (1984), Geothermal measurements in northern British Columbia and southern Yukon Territory, Can. J. Earth Sci.,21, 599-608.

Lewis, T.J., Hyndman, R.D., and P. Fluck (2003), Heat flow, heat generation and crustal temperatures in the northern Canadian Cordillera: Thermal control of tectonics, $J$. Geop. Res. 108(B6), doi:10.1029/2002JB002090. 
WOODBURY ET AL.: NORTHER LATITUDE GROUND-SURFACE-AIR TEMPERATURES X - 13

Lewis, T.J. and K. Wang (1998), Geothermal evidence for deforestation induced warming: Implications for the climatic impact of land development, Geop. Res. Lett. 25(4), 535538.

Majorowicz, J., Safanda J. and W. Skinner (2004), Past surface temperature changes as derived from continental temperature logs-Canadian and some global examples of application of a new tool in climate change studies, Advances in Geophysics, Vol 47, 113-176.

Majorowicz, J. and J. Safanda (2005), Measured versus simulated transients of temperature logsa test of borehole climatology, J. Geophys. Eng, 2, 1-8.

Mann, M.E. and G. Schmidt (2003), Ground vs. surface air temperature trends: Implications for borehole surface temperature reconstructions, Geop. Res. Lett., 30(12), doi:10.1029/2003GL017170.

Rodenhuis, D., Bennett, K. E., Werner, A. T., Murdock, T. Q. and D. Bronaugh (2007), Climate Overview 2007, Hydro-climatology and Future Climate Impacts in British Columbia, Pacific Climate Impacts Consortium, University of Victoria, Victoria, B.C., Canada.

Schmidt, G. and M.E. Mann (2004), Reply to comment on Ground vs. surface air temperature trends: Implications for borehole surface temperature reconstructions by D. Chapman et al. Geop Res. Lett.,31, L07206, doi:10.1029/2003GL019144.

Zhang, T. (2005), Influence of the seasonal snow cover on the ground thermal regime: An overview, Reviews of Geophysics, 43, 1-23. 
X - 14 WOODBURY ET AL.: NORTHER LATITUDE GROUND-SURFACE-AIR TEMPERATURES

Zhang, X., L. Vincent, W. D. Hogg, and A. Niitsoo (2000), Temperature and precipitation trends in Canada during the 20th century, Atmosphere-Ocean, 38 (3), 395-429. 
Figure 1. Whitehorse hole. Dashed line is regression line through the data. Solid back line, dash-dot both based on ramp signal from year 1800 .

Figure 2. Dease Lake. The black dots refer GSC observations 1966-1968. Most recent survey was in 2006, yellow. The dotted blue line is the best fit from the earlier GSC data. The thermal profile in purple was based on the soil temperatures determined from the VSMB model.

Figure 3. Hotailuh and Gnat Lake and Ritchie holes

Figure 4. Buckley Lake hole. 


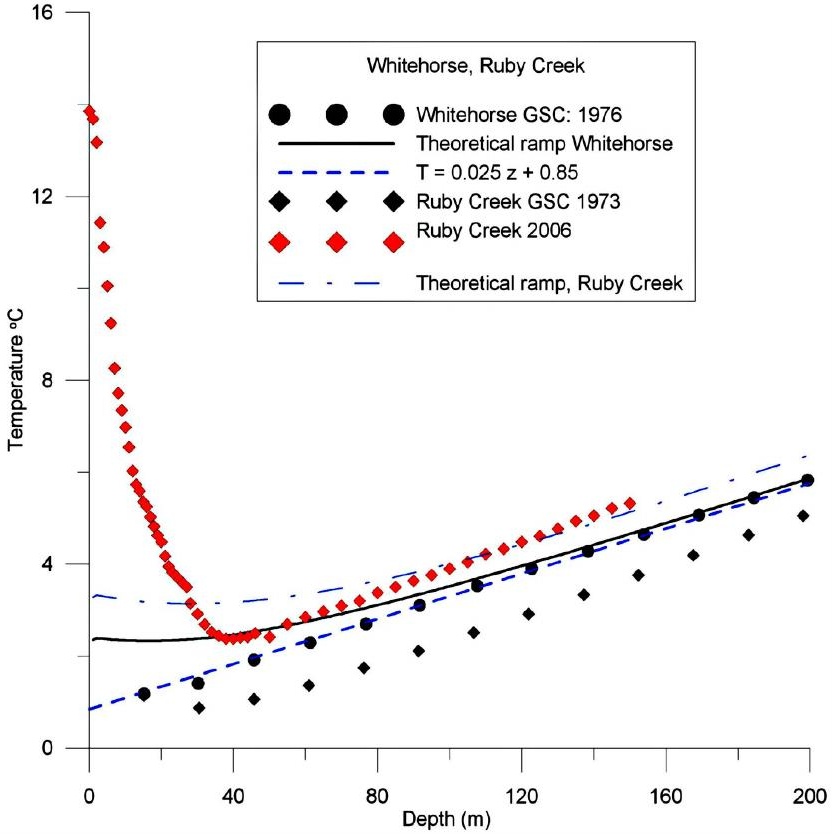




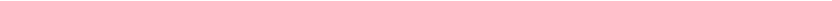




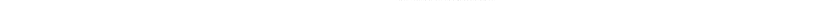




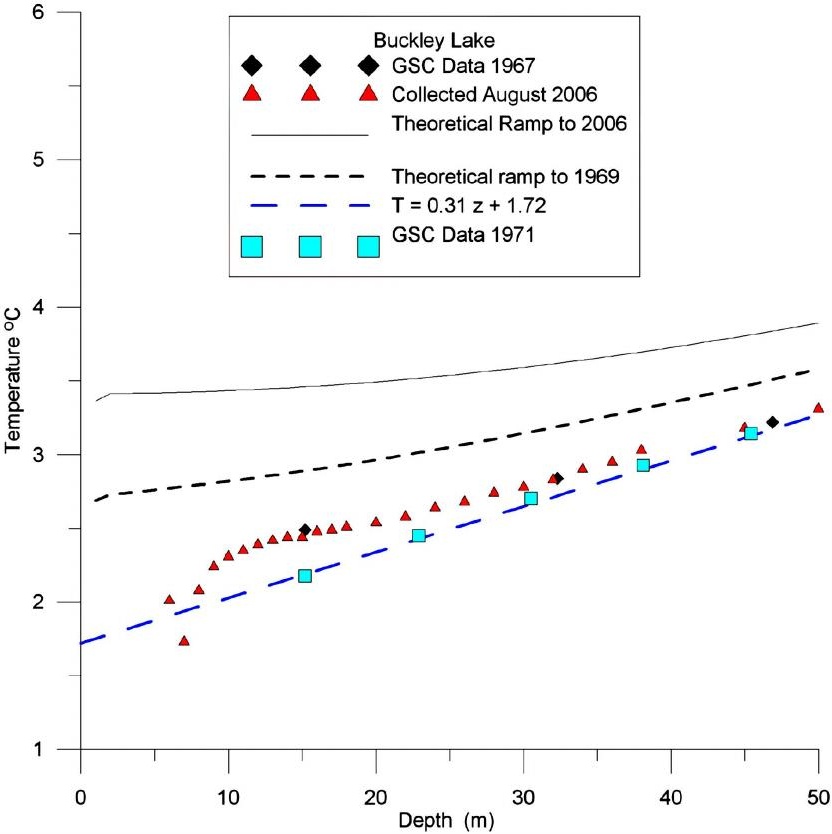

